\title{
Airborne Pollutant inside a Highway Tunnel Coated with a Photocatalytic Mortar
}

\author{
Luca Riderelli ${ }^{1}$, Edoardo Bocci ${ }^{1,2}$, Maurizio Bocci ${ }^{1}$, Gabriele Fava $^{1, *}$ \\ ${ }^{1}$ Department of Materials, Environmental Sciences and Urban Planning, Department of Construction, Civil Engineering and Architecture, \\ Università Politecnica delle Marche Via Brecce Bianche 12, Italy \\ ${ }^{2}$ Università Degli Studi E-Campus Via Isimbardi 10, 22060 Novedrate (CO), Italy
}

Copyright (C) 2015 Horizon Research Publishing All rights reserved.

\begin{abstract}
Air pollution measurements were carried out at the Cavallo highway tunnel in Ancona, Italy. The tunnel is used daily by an average of 20,000 vehicles, of which $25 \%$ are gasoline fueled passenger cars, $25 \%$ diesel cars, and $50 \%$ trucks. Tunnel air concentrations of carbon dioxide, carbon monoxide, volatiles organic compounds (VOC), aromatic hydrocarbons and Nitrogen Oxides $\left(\mathrm{NO}_{\mathrm{x}}\right)$ are presented. An integrated sampling-analysis strategy has been implemented in order to get evidence on photocatalytic processes involved inside a highway tunnel freshly coated with mortar containing photocatalytic $\mathrm{TiO}_{2}$. In situ measurements, rather than laboratory material testing, has offered an efficient way for evaluating the occurrence of photocatalytic reactions, in spite of the presence of many conflicting meteorological and traffic parameters. The $\mathrm{CO}_{2}$ level inside the tunnel after the photocatalytic mortar treatment resulted initially $22 \%$ lower than before treatment but it reduced to a $14 \%$ within 6 months. The consistent decreases of acetates, nitrites, and sulphates, together with the sensible increase of oxalates observed on carbon adsorbing panels, point to the occurrence of oxidative reactions occurring inside the coated tunnel. Further study is required to elucidate the effect of $\mathrm{NO}_{\mathrm{x}}$ adsorption, in order to be able to make predictions of the time-dependence on the de-polluting effect, or how the mortar is influenced by the relative humidity, as well as its composition and exposure history.
\end{abstract}

Keywords Photocatalysis, Sampling Strategy, Titania, Tunnel Air Pollution

\section{Introduction}

One of the most important environmental concerns regarding health problem in large metropolis, is devoted to the increasing urban air pollution. Motor vehicles are a significant source of air pollution and emit large quantities of carbon dioxide $\left(\mathrm{CO}_{2}\right)$, carbon monoxide $(\mathrm{CO})$, hydrocarbons $(\mathrm{HC})$, nitrogen oxides $\left(\mathrm{NO}_{\mathrm{x}}\right)$, particulate matter $(\mathrm{PM})$, air toxic substances such as Benzene, Ethyl Benzene, Toluene, Xilenes (BTEX), and many others. Each of these, along with secondary by-products such as ozone and secondary aerosols (e.g., nitrates and inorganic \& organic acids), can cause adverse effects on the health of the people and the environment. Of course, traffic emissions are more relevant in areas close to the main streets or directly near the exhaust pipes of the vehicles. Where possible, the most effective process needs to be identified in order to de-pollute the air from these emissions.

As the awareness of the potential effects of air pollutants on people health has grown ${ }^{1-2}$, more stringent emissions controls have been implemented for reducing the primary emissions from motor vehicles. On the other side, recent research activities are focusing on the more broadly dispersed secondary pollutants, such as ozone $\left(\mathrm{O}_{3}\right)$, that are derived from these emissions.

A suggestive, unconventional approach with the aim to remove the pollutants from the air, has been reported in the literature ${ }^{3-5}$. Photocatalytic Titanium dioxide $\left(\mathrm{TiO}_{2}\right)$ embedded in cementitious materials, combining adsorbing and reactive surfaces, can produce a microstructure for photo-degradative processes. It has been demonstrated that both organic pollutants and oxides such as $\mathrm{NO}, \mathrm{NO}_{2}$ and $\mathrm{SO}_{2}$, at low concentration levels, can be treated by $\mathrm{TiO}_{2}$ under UV irradiation. The mechanism of pollution decomposition is illustrated by Fig. 1 . 


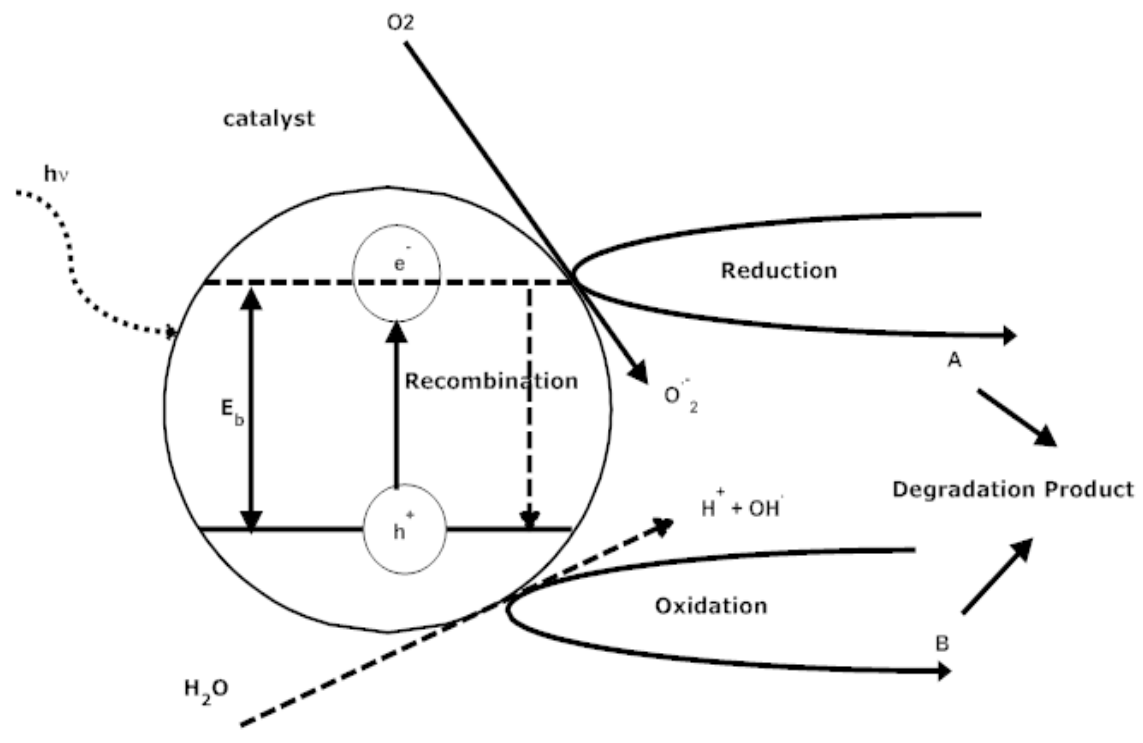

Figure 1. Overall scheme showing the pathway of the photocatalytic reactions

The reaction begins with the irradiation of light over $\mathrm{TiO}_{2}$. When a photon containing the energy equal to or larger than the band gap is present, an electron will be promoted from the valence-band to the conduction-band generating "holes" (electron vacancy) in the valence-band. In this reaction, $\mathrm{h}^{+}$ and $\mathrm{e}^{-}$are powerful oxidizing and reducing agents, respectively. The strong oxidation power of $\mathrm{h}^{+}$enables it to reacts with water to generate the highly active hydroxyl radical, which is also a powerful oxidant. The de-pollution effect of photocatalytic cementitious materials has been demonstrated by many laboratory studies ${ }^{6-15}$. The present paper deals with the application of $\mathrm{TiO}_{2}$ based cementitious mortars inside a highway tunnel, with the objective to quantify the potential of this method to reduce air pollution. The pollution level inside the tunnel has been analysed by means of both laboratory and field studies. For the in situ measurements, specific measuring campaigns, including continuous monitoring and grab sampling, were carried out with the aim of detect photocatalytic reactions. The research program also included the evaluation of mortars samples in order to investigate the effectiveness with time and the aging process. The monitored compounds were: $\mathrm{SO}_{\mathrm{x}}, \mathrm{NO}_{\mathrm{x}}, \mathrm{CO}$, $\mathrm{CO}_{2}, \mathrm{O}_{3}$ and BTEX. The analysis focused on the aspects related to vehicular traffic emissions, macro- and micro-climate conditions, and reduction of air pollutants.

\section{Tunnel Description and Materials Used}

The testing strategy was designed relying on existing procedures based on pump sampling protocols or by designing and testing new sampling approaches based on passive sampling by means of adsorbent panels. This new approach was developed, step-by-step, during the whole campaign, matching the data obtained with those obtained by the traditional methods. All the analyses were intended to describe the ambient air quality. The geometrical characteristics of the highway tunnel are shown in Table 1.

Table 1. Main characteristics of the tunnel

\begin{tabular}{|c|c|}
\hline Length (Northbound) & $499 \mathrm{~m}$ \\
\hline Length (Southbound) & $501 \mathrm{~m}$ \\
\hline By-pass location & Middle \\
\hline Slope & $\pm 1 \div 2 \%$ \\
\hline Section area & $33 \mathrm{~m}^{2}$ \\
\hline Section perimeter & $26.1 \mathrm{~m}$ \\
\hline Width & $9.31 \mathrm{~m}$ \\
\hline Internal surface area & $9500 \mathrm{~m}^{2}$ \\
\hline Internal treated surface area & $6300 \mathrm{~m}^{2}$ \\
\hline Vehicles/h & Up to 1600 \\
\hline
\end{tabular}

The lateral surfaces of the internal tunnel walls, not directly exposed to the solar radiation but lighted with UV-A lamps, were coated with a commercial photoactive mortar containing $\mathrm{TiO}_{2}$. The measure of the air quality directly inside the tunnel was considered the best way to have a full-scale overview of the photocatalytic reactions. Absorbing panels made with activated carbons sheets (Fig.2) were positioned at the entrance of the northbound tunnel (Panel 1) and inside the internal by-pass of the tunnel (Panel 2).

$\mathrm{NO}_{\mathrm{x}}$ oxidation test on mortar samples were performed according to the Italian standard UNI 11247 and European Standard ISO $679[11,12]$. The conceptual model assumed the tunnel as a close volume, characterised by natural ventilation ("piston effect"). 


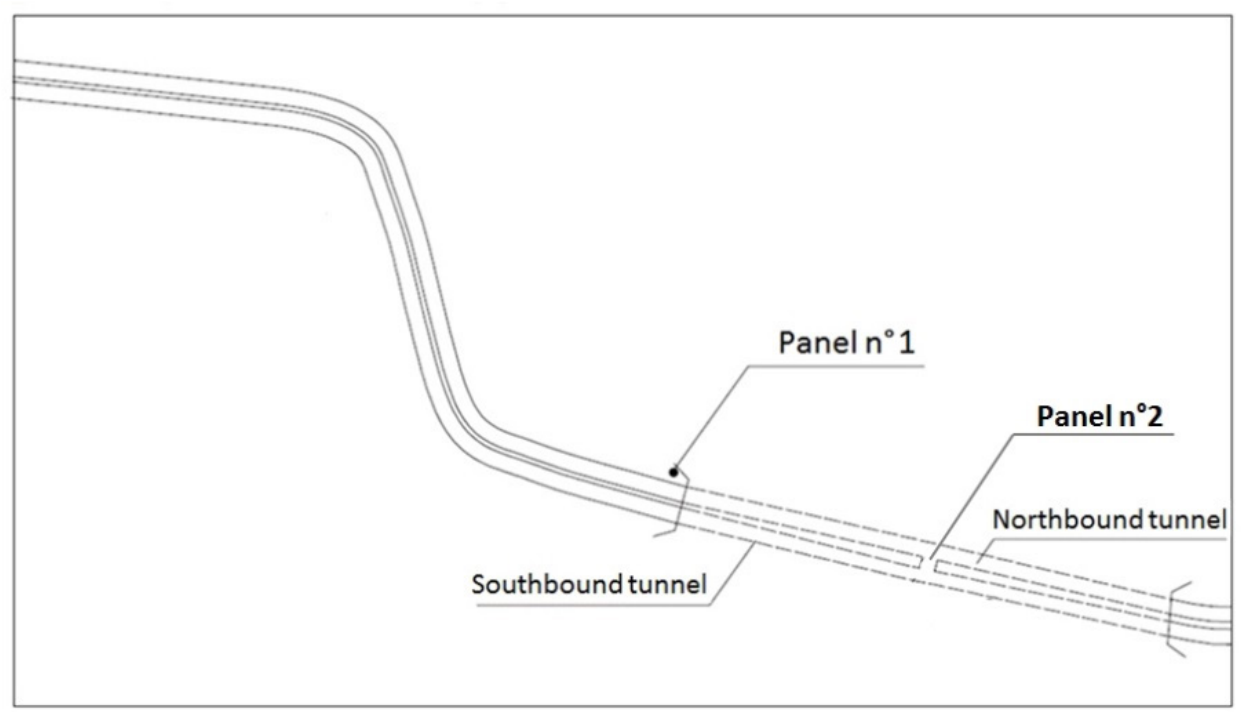

Figure 2. Two lane tunnel with internal by-pass

\section{Monitoring Design}

Numerous variables were considered in designing a monitoring net, including many in situ variables that influence materials' efficiency, such as coating, illuminating system, meteorological conditions and vehicular traffic.

The sampling strategy adopted for this research was based on two different options: discrete sampling and continuous monitoring. Within the discrete sampling systems, three modes considered were:

1. Fixed panels realized with sheets of activated carbon;

2. Commercially available Radiello® passive samplers;

3. Direct sampling, realized either through two litres size empty steel cylinders for air collection, or drilled cans filled with nonwoven fabrics soaked with an absorbing solution in order to filter the air.

Activated carbon panels and Radiello ${ }^{\circledR}$ samples were localized both at the northbound portal and inside the tunnel, far from the by-pass (in the middle of the tunnel), with the objective to accumulate the airborne pollutants during the time of their exposure. Two steel cylinders were simultaneously used for collecting air samples at the northbound lane (tunnel coated with $\mathrm{TiO}_{2}$ ), and in the Southbound lane (normally painted). The cylinders were vacuum-emptied before collecting the air samples. A further direct sampling mode consisted in absorbing cans mounted on a car travelling inside the tunnel at the fixed speed of about $80 \mathrm{~km} / \mathrm{h}$. Steel cylinder and nonwoven fabrics samples were taken together the same day. Chemical analyses on the collected samples were carried out within two hours from sampling, in order to reduce the delay as much as possible.

Continuous monitoring was carried out during three campaigns: one before and two after the tunnel treatment. Instruments were installed inside a box near the northbound portal, and also inside the by-pass. Samples of tunnel air were analysed with a ten minutes frequency for a period of
38 to 52 hours.

\section{Instruments}

Passive samplers (activated carbon, Radiello ${ }^{\circledR}$ samplers, nonwoven fabrics) were analysed in laboratory with a Gas Chromatograph, C. Erba Mod. GC800Top, for Benzene, Ethylbenzene, Toluene, Xylene (BTEX), and VOCs, and with an Ionic Chromatograph, DIONEX mod. 4500i, for acetates, chlorides, nitrites, nitrates, sulphates and oxalates.

Air samples were also subjected to VOCs analyser (PID technique, mod. Ppb Rae Plus), and to Multigas Monitor IR, photoacustic analyser, Bruël\&Kjær Mod. 1302, for $\mathrm{CO}, \mathrm{CO}_{2}$, aliphatic hydrocarbons $\mathrm{CH}$, and $\mathrm{H}_{2} \mathrm{O}$, and to $\mathrm{NO} \div \mathrm{NO}_{\mathrm{x}}$ chemiluminescence analyser Monitor Labs Mod. 8841.

\section{Meteorological and Traffic Data}

Chemical data from the tunnel air were matched with meteorological and traffic data coming from local monitoring stations owned by the highway department. It was observed that for a typical weather condition, there were wind rotation caused by the influence of convection cell of the nearby sea and land breezes. Concerning the tunnel exposition to wind, it was observed that the prevalent winds persist mostly in the direction opposite to the traffic flux. In this condition, a sort of cap-effect occurs on the northbound portal, amplifying the concentration of polluting agents in the tunnel.

Traffic data indicate that the number of cars is comparable with the number of trucks/lorries during the weekdays, while the cars are prevalent during the weekend. On average, the traffic flow rate on weekdays were from 200-1600 vehicles/hr nearby the inlet of northward channel and 208-1,500 vehicles/hr nearby the inlet of southward channel, respectively. Light duty trucks comprised $37 \%$ to $77 \%$ (average $40 \%$ ) of vehicles. 
Table 2. Example of wind direction quantification

\begin{tabular}{|c|c|c|c|c|c|}
\hline \multirow{2}{*}{ Dates } & \multirow{2}{*}{ Days } & \multicolumn{2}{|c|}{ Data analysis North, East } & \multicolumn{2}{c|}{ Data analysis North, West } \\
\cline { 3 - 6 } & & North-West & South-East & North-East & South-West \\
\hline $21 \mathrm{Jan} \div 4 \mathrm{Feb}$ & 15 & 1238 & & 257 & \\
\hline $4 \mathrm{Feb} \div 18 \mathrm{Feb}$ & 15 & 1158 & & 387 & \\
\hline $18 \mathrm{Feb} \div 4 \mathrm{Mar}$ & 15 & 316 & & 540 & \\
\hline $4 \mathrm{Mar} \div 18 \mathrm{Mar}$ & 15 & 452 & & 999 & \\
\hline $18 \mathrm{Mar} \div 31 \mathrm{Mar}$ & 16 & & -20 & 667 & \\
\hline $31 \mathrm{Mar} \div 15 \mathrm{Apr}$ & 14 & 158 & & 506 & \\
\hline $15 \mathrm{Apr} \div 29 \mathrm{Apr}$ & 15 & 418 & & 651 & \\
\hline $29 \mathrm{Apr} \div 13 \mathrm{May}$ & 15 & & -345 & 471 & \\
\hline $13 \mathrm{May} \div 21 \mathrm{May}$ & 8 & 494 & & 757 & \\
\hline
\end{tabular}

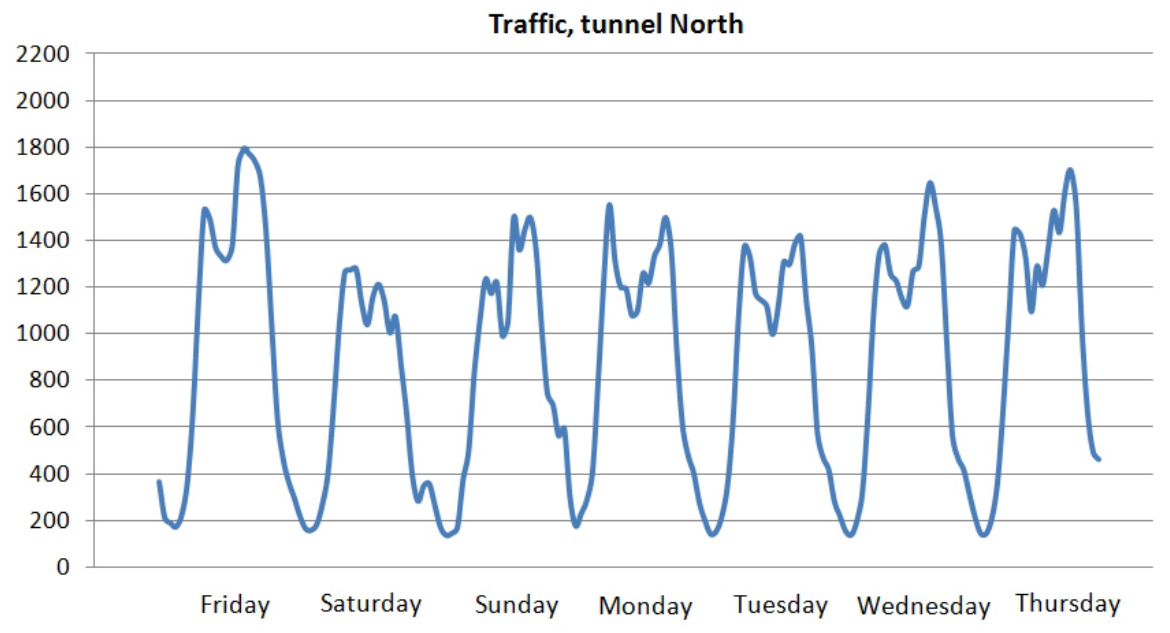

Graph 1. Example of traffic in tunnel North

\section{Results}

$\mathrm{CO}_{2}, \mathrm{CO}$, and $\mathrm{VOC}$ levels were continuously monitored for a period of 32 to 58 hours, at the northbound portal of the tunnel, before and after the coating treatment with the photocatalytic mortar. Summary statistics for $\mathrm{CO}_{2}, \mathrm{CO}, \mathrm{CH}$, and $\mathrm{H}_{2} \mathrm{O}$ (humidity $\mathrm{mg} / \mathrm{m}^{3}$ ) levels monitored during the identified three periods are described on Table 3 and 4 . The hourly variation in traffic density inside the tunnel (Graph 1), and the related pollutants emissions, are well reproduced by the diurnal $\mathrm{CO}_{2}$ evolution as illustrated in Graph 2 which shows the air concentration history monitored during 3 day period in January, April and May (Wednesday to Saturday). On working days, peak concentrations of all pollutants occur in the morning from 7 to 9 A.M. and in the evening from 4 to 6 P.M. It is obvious that the pollution levels in the tunnel are determined primarily by the traffic intensity, of which the pattern is shown in Graph 1. In Italy, on the highway system, the normal driving speed is $120 \mathrm{~km} / \mathrm{h}$, speed that provides a natural ventilation and supply fresh air within the tunnel (so called piston effect). It should be noted that with this traffic mode, air velocities result in the range of $3-5 \mathrm{~m} / \mathrm{s}$ and the influence exerted on the airflow properties generally overcome the outside ventilation. Analysis of the air pollution data in combination with traffic volume indicates that $\mathrm{CO}_{2}$, hydrocarbon and $\mathrm{NO}_{\mathrm{x}}$ emissions change following the mortar treatment. Comparing the data for three monitored periods (before treatment labelled $\mathrm{CO}_{2}$, first month after treatment labelled $\mathrm{CO}_{2} 1$ and six months after treatment labelled $\mathrm{CO}_{2} 2$, respectively in December, January, and May), it can be observed that the $\mathrm{CO}_{2}$ level shows a clear initial reduction, followed by a slow recovery, month after month (Graphs 2 and 3). The same trend is substantially observed also for $\mathrm{CO}$ and VOC as registered by the IR monitoring inside the tunnel. On the complex, the results in Table 3 and 4 suggest an adsorption process, initially established on the freshly coated surfaces and then followed by a loss of capacity after few months of exposition. Therefore, no clear evidence of photocatalytic reactions can be inferred by these data.

Analyzing the results achieved by the Radiello ${ }^{\circledR}$ sampling strategy and fixed panel adsorption sheets, some more interesting results appear. The sources of pollution and some chemical reactions before (BT) and after (AT) the photocatalytic mortar treatment, experience a controversial effect. The aromatic hydrocarbons concentrations (Benzene, Toluene and Xilene, Table 6, Graphs 4,5,6) show no variation or only a low increase. 
Table 3. Summary statistics for $\mathrm{CO}_{2}(\mathrm{ppm})$ and $\mathrm{CO}(\mathrm{ppm})$

\begin{tabular}{|c|c|c|c|c|c|c|}
\hline & $\mathrm{CO} 2$ & $\mathrm{CO} 2 \_1$ & $\mathrm{CO}_{-} \_$ & $\mathrm{CO}$ & $\mathrm{CO}_{-} 1$ & $\mathrm{CO} \_2$ \\
\hline Count & 282 & 351 & 551 & 282 & 351 & 551 \\
\hline Average & 529.7 & 468.5 & 503.4 & 0.522 & 0.841 & 0.671 \\
\hline Standard deviation & 51.16 & 14.55 & 31.97 & 0.5580 & 0.2146 & 0.7716 \\
\hline Coeff. of variation & $9.66 \%$ & $3.106 \%$ & $6.35 \%$ & $106.9 \%$ & $25.52 \%$ & $11.49 \%$ \\
\hline Minimum & 427.0 & 440.0 & 438.0 & -0.488 & 0.205 & 5.25 \\
\hline Maximum & 669.0 & 519.0 & 703.0 & 6.02 & 2.0 & 12.2 \\
\hline Range & 242.0 & 79.0 & 265.0 & 6.508 & 1.795 & 6.950 \\
\hline
\end{tabular}

Table 4. Summary statistics for $\mathrm{CH}$ (ppm) and for $\mathrm{H}_{2} \mathrm{O}$ (ppm)

\begin{tabular}{|c|c|c|c|c|c|c|}
\hline & CH & CH_1 & CH_2 & H2O & H2O_1 & H2O \\
\hline Count & 282 & 351 & 551 & 282 & 351 & 551 \\
\hline Average & 3.82 & 2.87 & 3.00 & 12,240 & 8,069 & 13,070 \\
\hline Standard deviation & 0.360 & 0.254 & 0.32 & $1,217.0$ & 354.5 & $1,089.0$ \\
\hline Coeff. of variation & $9.4 \%$ & $8.8 \%$ & $10.8 \%$ & $9.945 \%$ & $4.393 \%$ & $8.333 \%$ \\
\hline Minimum & 2.78 & 1.08 & 2.42 & 10,500 & 5,610 & 11,000 \\
\hline Maximum & 4.95 & 4.70 & 4.01 & 14,700 & 8,460 & 15,400 \\
\hline Range & 2.17 & 3.62 & 1.59 & 4,200 & 2,850 & 4,400 \\
\hline
\end{tabular}

Conversely, different figures arise from the activated carbon panels analyses. Sensible decreases of acetates, nitrites, sulphates, and an increment of oxalates are observed when the UV-A lamps were switched on (AT period on Graphs 7-11).

It can be argued that a photocatalytic Ozone-NOx cycle induced by $\mathrm{TiO}_{2}$ photocatalytic process may have produced an oxidation of $\mathrm{NO}$ and $\mathrm{SO}_{2}$ to $\mathrm{NO}_{2}$, Nitrates and Sulphates, followed by a strong adsorption on the fresh mortar surface while only a week physical adsorption process may be responsible for the fate of the aromatic hydrocarbons.

An additional indication comes from the chemical composition of the airborne tunnel aerosol obtained by the discrete sampling. From the instant sample analysis (Tables
5), it is possible to notice the different values between the paired samples taken simultaneously in the northbound (NB) and southbound (SB) directions. The higher levels of $\mathrm{NO}_{2}$ in the coated lane must be considered, as the result of a photocatalytic activity considering that the NO levels remain substantially equals within the treated and untreated lane.

Considering the results obtained by sampling strategies, it can be concluded that despite various weather conditions that have characterized the periods of investigation (sunny, cloudy, rain, wind direction and insistence on the two different tubes), conditions that reduce air pollution in the road tunnel were reached. Oxalates, Nitrates production, and $\mathrm{NO}_{2}$ and acetates reduction described on Graphs 7-11 clearly prove the photochemical oxidation effect carried on by the $\mathrm{TiO}_{2}$ mortar employed. However, the effectiveness of the oxidation process, calculated as the difference between $\mathrm{CO}_{2}$ levels in the cylinders air in both tubes of the tunnel, is certainly lower than that obtained in the microcosm created in the laboratory and measured following the directions of the UNI 11247. Furthermore, it appears clearly a continuous efficiency decrease within the tunnel during time. In fact, the mortar surface of the tunnel at that time appeared significantly deteriorated

Table 5. Summary Statistics for $\mathrm{NO}_{2}, \mathrm{NB}-\mathrm{NO}_{2}, \mathrm{SB}$ and $\mathrm{NO}, \mathrm{NB}-\mathrm{NO}$, SB

\begin{tabular}{|c|c|c|}
\hline & $\mathrm{NO}_{2}, \mathrm{NB}-\mathrm{NO}_{2}, \mathrm{SB}$ & $\mathrm{NO}, \mathrm{NB}-\mathrm{NO}, \mathrm{SB}$ \\
\hline Count & 8 & 8 \\
\hline Average & 4.5 & 0.08388 \\
\hline Standard deviation & 11.78 & 0.1652 \\
\hline Coeff. of variation & $261.9 \%$ & $197.0 \%$ \\
\hline Minimum & -17.0 & -0.271 \\
\hline Maximum & 20.0 & 0.259 \\
\hline Range & 37.0 & 0.53 \\
\hline
\end{tabular}

\section{Carbon Dioxide (ppm) Before and After Treatmen}

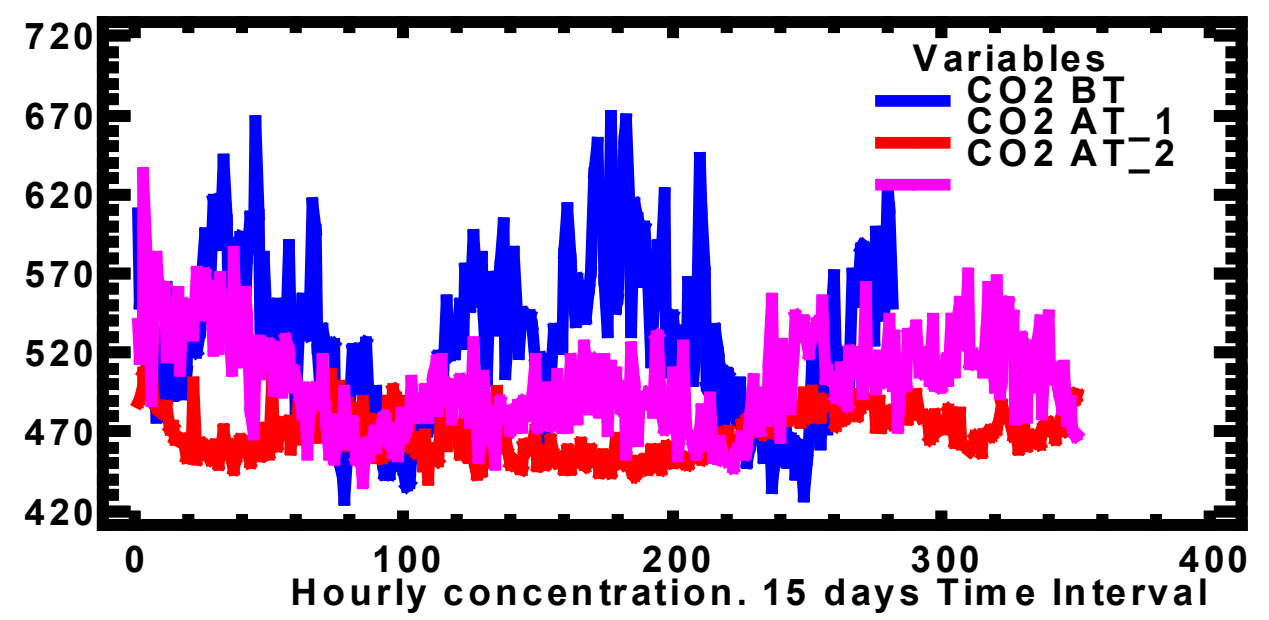

Graph 2 


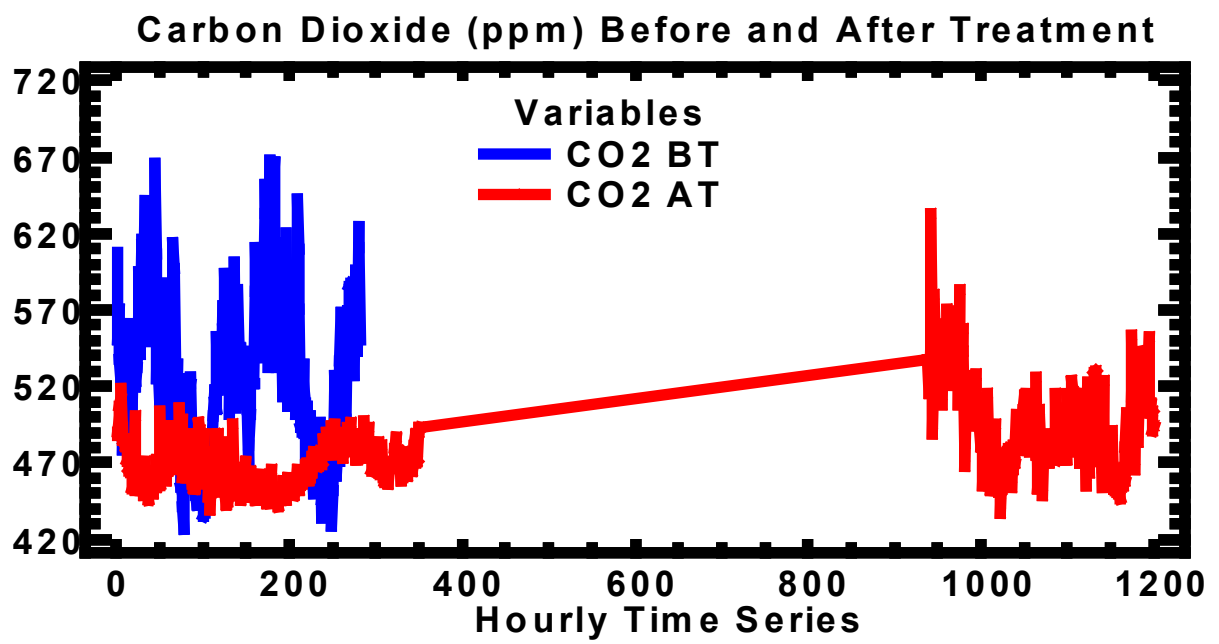

Graph 3

Graphs 2 and 3. Hourly $\mathrm{CO}_{2}$ evolution inside the tunnel before a painting treatment (blue dots) and after $\mathrm{TiO}_{2}$ painting treatment (pink and red dots). $\mathrm{CO}_{2}$ time evolution after one months and six months from the treatment (red dots).

Table 6. Summary statistics of airborne concentration levels inside the tunnel

\begin{tabular}{|c|c|c|c|c|c|r|}
\hline & \multicolumn{2}{|c|}{ Benzene $\left(\mu \mathrm{g} / \mathrm{m}^{3}\right)$} & \multicolumn{2}{c|}{ Toluene $\left(\mu \mathrm{g} / \mathrm{m}^{3}\right)$} & \multicolumn{2}{c|}{ Xilenes $\left(\mu \mathrm{g} / \mathrm{m}^{3}\right)$} \\
\hline Period of interest & B_T & A_T & B_T & A_T & B_T & A_T \\
\hline Average & 4.33 & 5.50 & 5.46 & 6.56 & 4.42 & 4.37 \\
\hline Standard Deviation & 2.35 & 2.26 & 2.16 & 2.19 & 1.73 & 1.41 \\
\hline
\end{tabular}

(B_T) before the treatment; (A_T) after the treatment

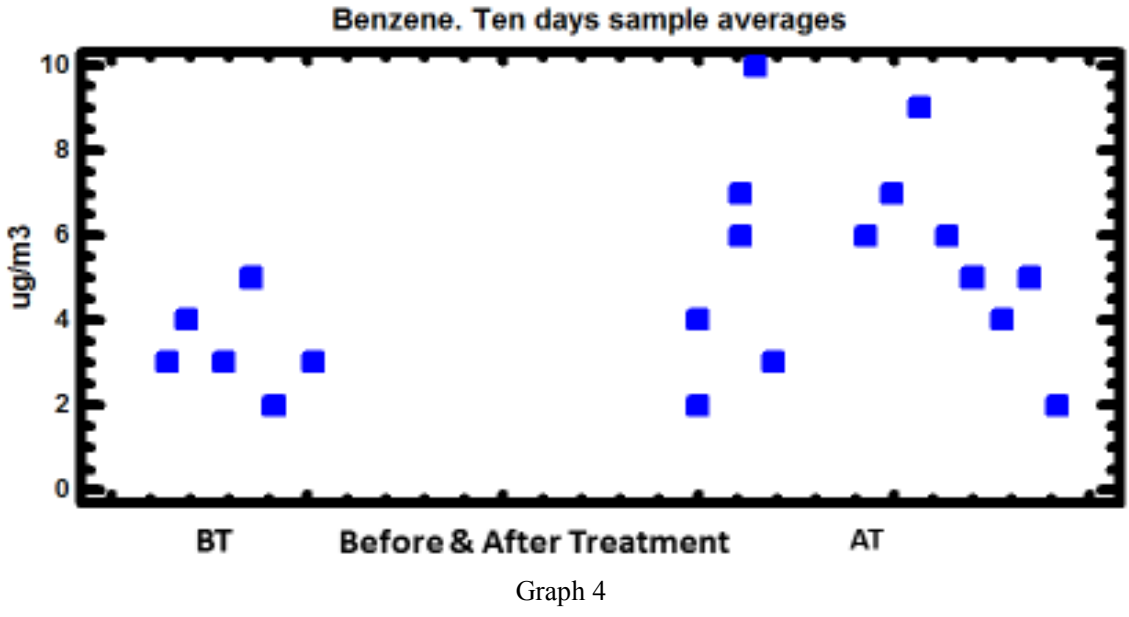

Toluene. Ten days sample averages

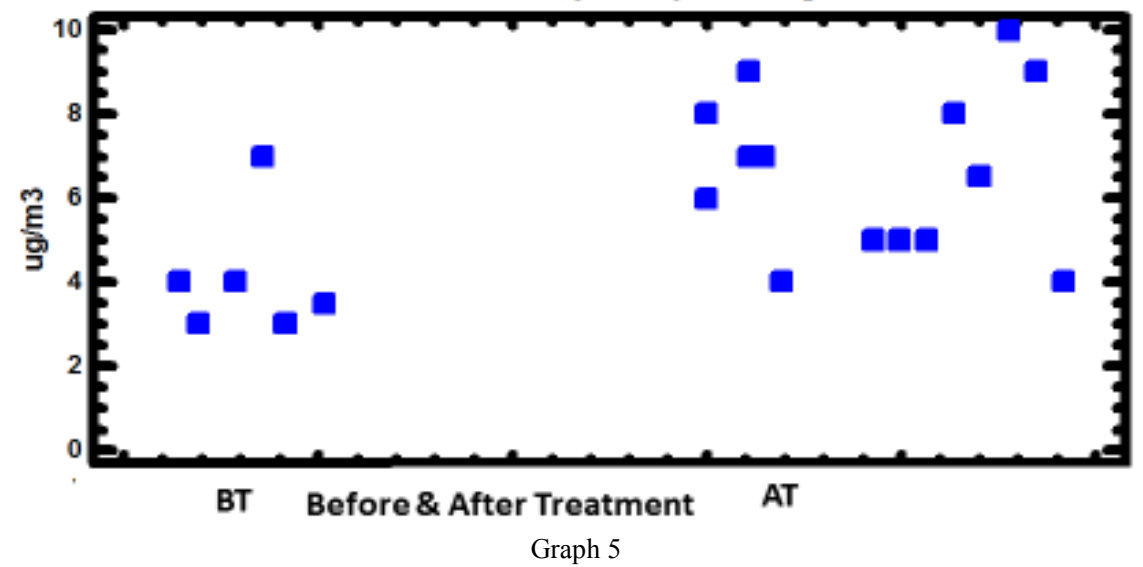




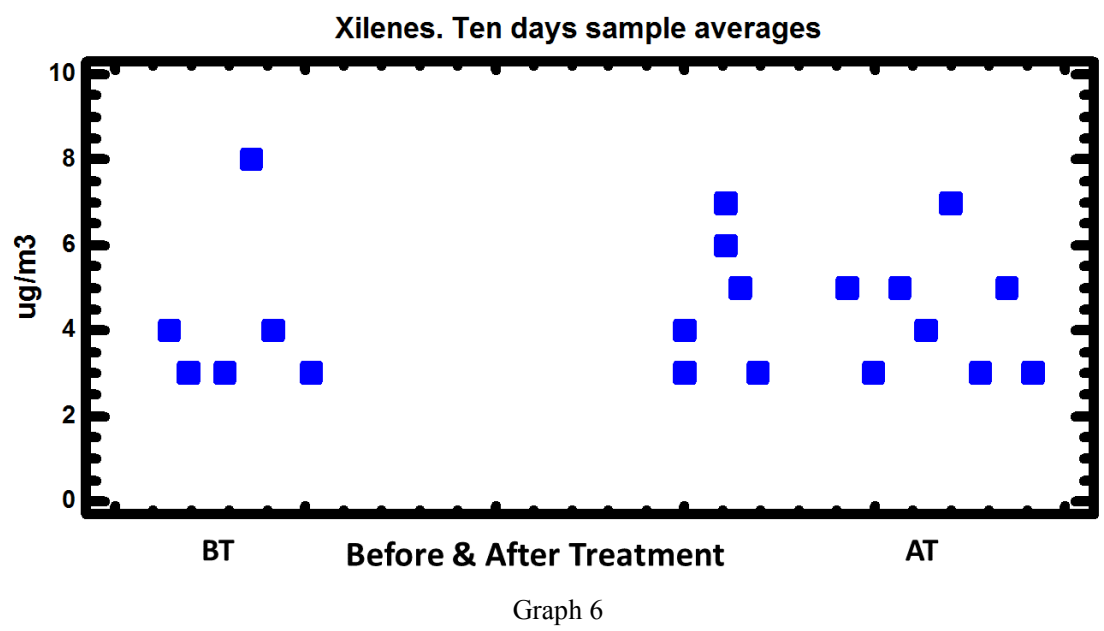

Graphs 4-6. Benzene, toluene, xylene data overlap (Radiello ${ }^{\circledR}$ samplers), tunnel with traditional paint and after $\mathrm{TiO}_{2}$ treatment..

Acetates (ppm), before (BT) and after (AT) treatment

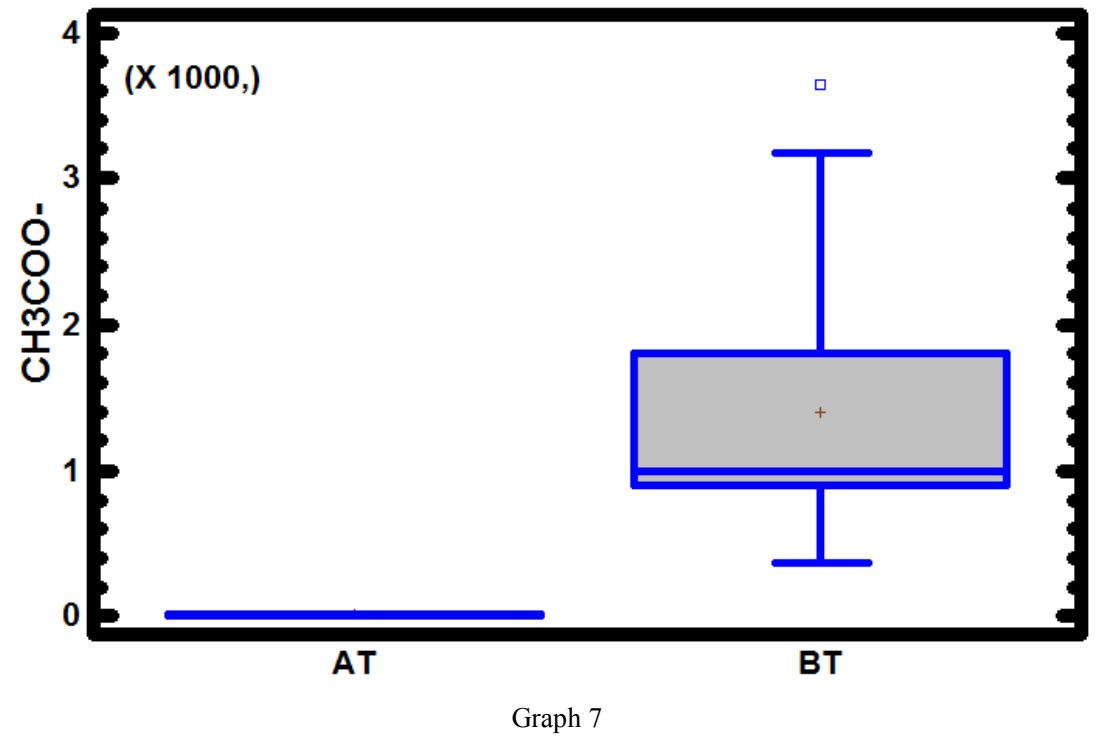

Nitrites (ppm), before (BT) and after (AT) treatment

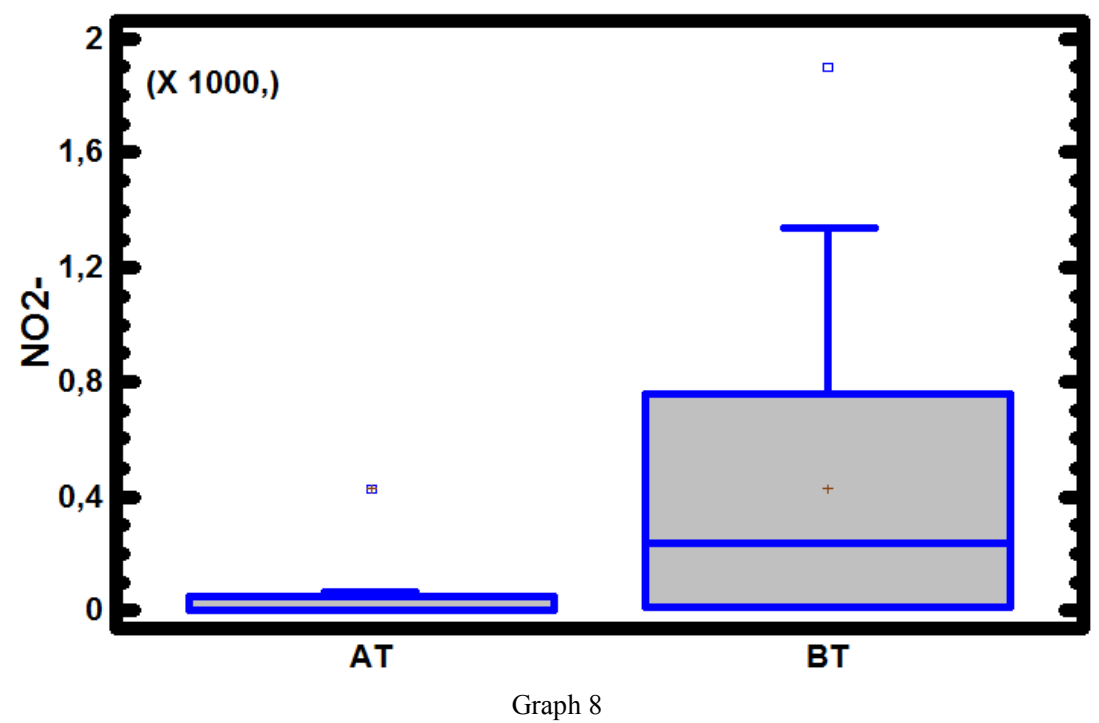


Nitrates (ppm), before (BT) and after (AT) treatment

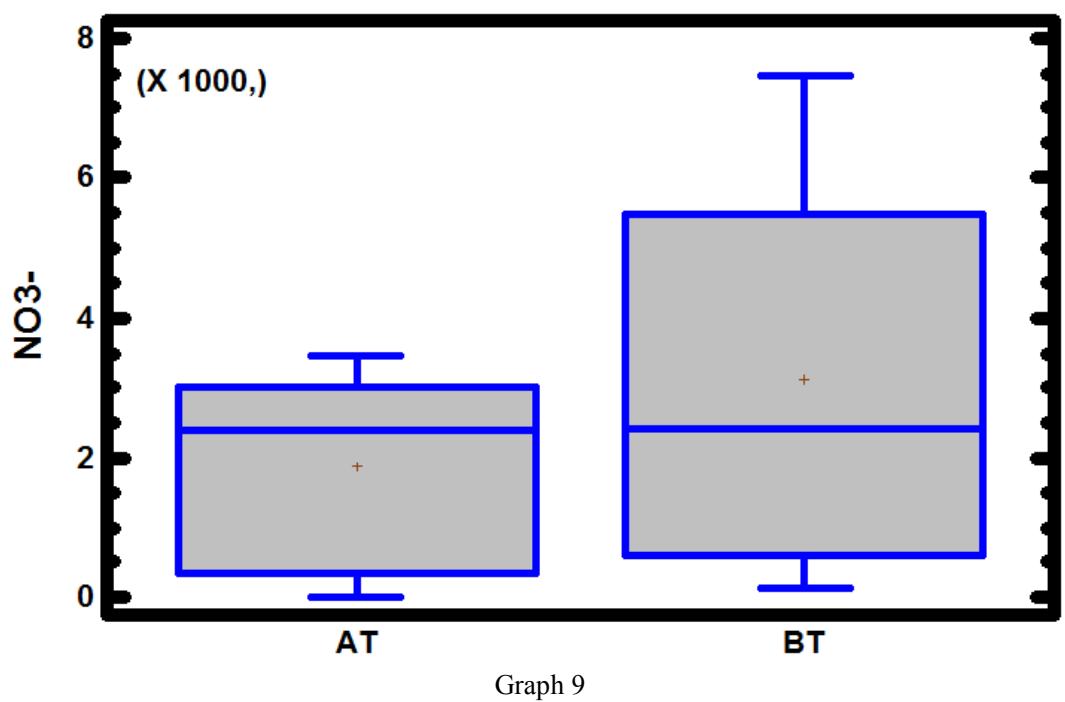

Sulphates (ppm), before (BT) and after (AT) treatment

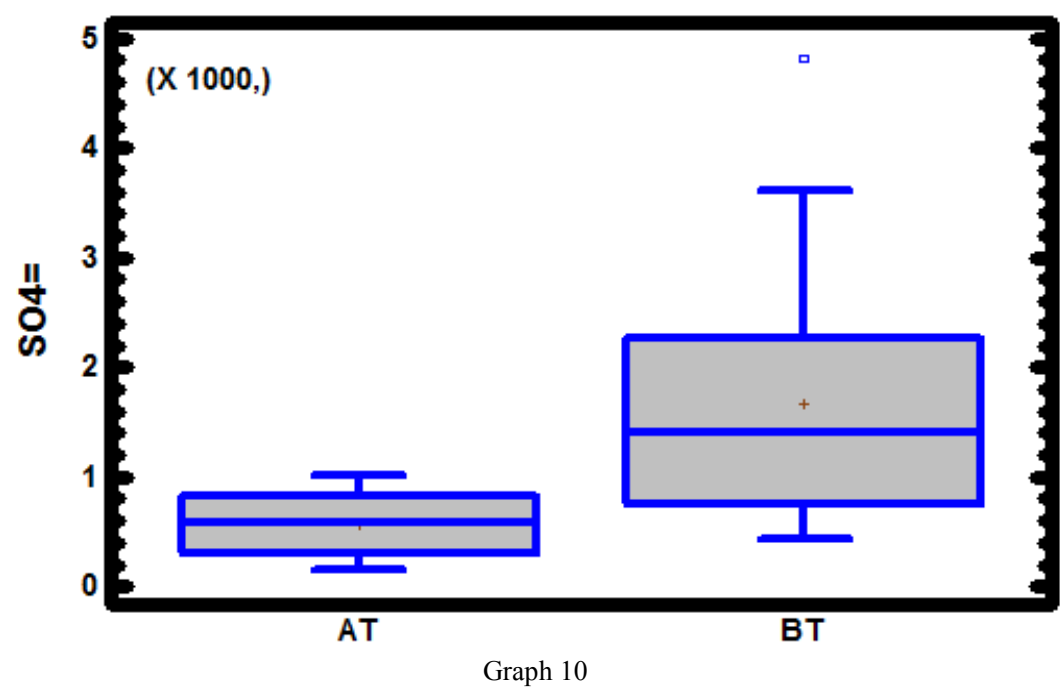

Oxalates (ppm), before (BT) and after (AT) treatment

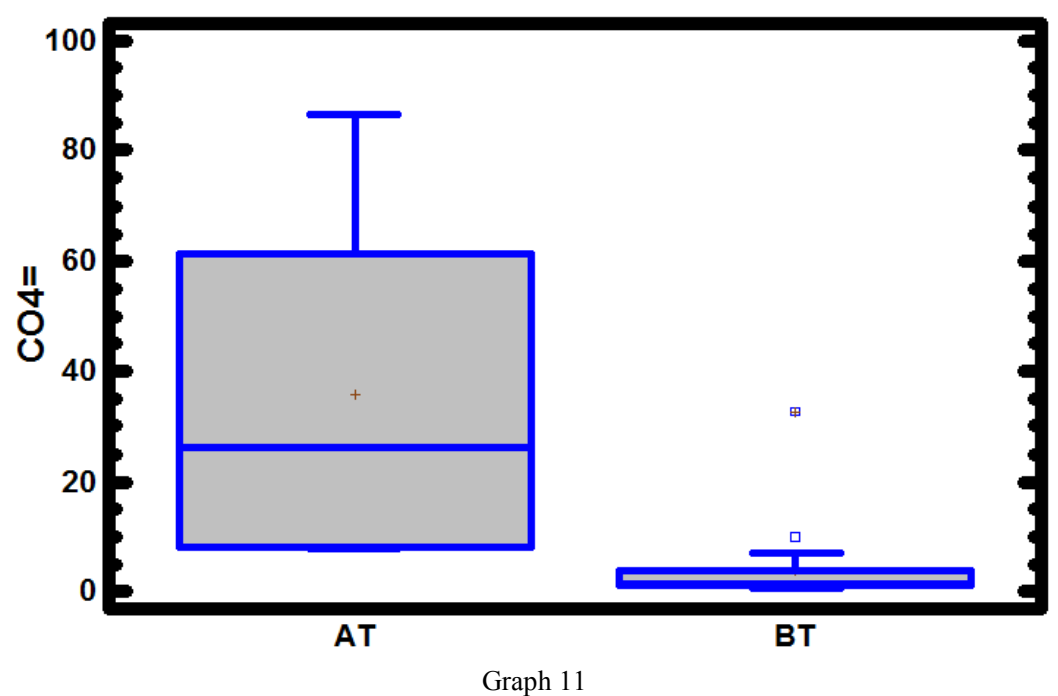

Graphs 7-11. Acetates, chlorides, nitrite, nitrates, sulphates and oxalates. Before (BT) and after (AT) treatment with $\mathrm{TiO}_{2}$ mortars. 


\section{Conclusions}

A sampling-analysis strategy composed by a combination of fixed adsorption panels, commercially passive sampler and instant air samples grabs has been implemented for studying the air pollution inside a highway tunnel freshly coated with mortar containing $\mathrm{TiO}_{2}$. A continuous monitoring with automatic analyser was also employed for a three period campaign, conducted before and after the photocatalytic treatment on the tunnel surface. The assembled strategy makes it possible to speculate on adsorption or photocatalytic processes by in situ measurements rather than on laboratory material testing. On the other end the actual real-scale conditions, with variables meteorological conditions (sunny, cloudy, windy, and rainy) and traffic density, makes difficult any environmental comparison. The monitored $\mathrm{CO}_{2}$ levels in the tunnel after the mortar treatment resulted initially lower by a $22 \%$ but decreasing to a $14 \%$ within 6 months. Oxidation reaction rates $\left(\mathrm{NO}_{2}\right.$ and $\mathrm{CO}_{2}$ production) appeared not obvious or considerably lower in comparison to the results obtained by direct testing of samples in the laboratory according to the procedure described in the UNI 11247. BTEX time series analyses did not manifested significant trend.

The manifold sampling analysis used (Radiello ${ }^{\circledR}$ passive samplers, adsorbent panels, cylinder air volumes, traps with non-woven fabrics) made any way possible to note the occurrence of photocatalytic reactions, even if in the presence of many confounding meteorological and traffic parameters. The consistent reduction of acetates, nitrites, and sulphates, together with the sensible increase of oxalates on the carbon adsorbing panels, indicate the occurrence of oxidative reactions inside the coated tunnel. Anyway, further study is required to understand the effect of $\mathrm{NO}_{\mathrm{x}}$ adsorption on the mortar in order to be able to make accurate predictions of the time-dependence of the de-polluting effect, and how the mortar is influenced by the relative humidity, as well as its composition and exposure history.

Incidentally, the suggestive benefits offered by adopting $\mathrm{TiO}_{2}$ photocatalytic surfaces must be viewed not only in the removing of pollutants, but possibly in the self-cleaning capacity of these surfaces. They can assure a white surface colour and a consequent increase of the safety for the drivers, due to the higher visibility. The evidence and quantification of these capacities is the aim of different surveys now in progress.

\section{REFERENCES}

[1] Burr ML, et Al. Effects on respiratory health of a reduction in air pollution from vehicle exhaust emissions; Occup. Environ.
Med. 61:212-218. (2004).

[2] Baldauf RW, Crews W, Snow R, Gabele P. Criteria and air toxic emissions from in-use, low emission vehicles. J Air Waste Manag. Assoc. 55:1263 1268 (2005);

[3] M.M. Ballari, H.J.H Browser. "Full Scale demonstration of Air Purifying pavement Journal of Hazardous Materials (2013) 406-414;

[4] Riderelli L., Fava G. "Photochemical Potential of Titania Painting at a Highway Tunnel Portal. Comparison with the Conditions Measured On Site.ISBN 978-), Rimini (Italy) (2010).

[5] Wang H., Wu Z., Zhao W., Guan B. "Photocatalytic Oxidation of Nitrogen Oxides Using $\mathrm{TiO}_{2}$ Loading on Woven Glass Fabric Chemosphere 66 185-190. (2007);

[6] C.S. Poon, E. Cheung. "NO removal efficiencies of photocatalytic paving blocks prepared with recycled materials Construction and Building Materials 21, 1746-53 (2006);

[7] Lixin Cao. et al., "Photocatalytic Oxidation of Toluene on Nanoscale $\mathrm{TiO}_{2}$ Catalysts: Studies of Deactivation and Regeneration. "Journal of Catalysis 196, 253-261 (2000)";

[8] Obee T.N., Brown., R.T. " $\mathrm{TiO}_{2}$ Photocatalysis for Indoor Air Applications: Effects of Humidity and Trace Contaminant Levels on the Oxidation Rates of Formaldehyde, Toluene, and 1,3-Butadiene. "Environ. Sci. Technol. 29 1223-1231 (1995)";

[9] Hoffmann, M. R.; Martin, S. T.; Choi, W.; Bahnemann, D. W "Environmental Applications of Semiconductor Photocatalysis" Chem. Rev (1), 69-96"(1995);

[10] Qi, C.; Stanley, N.; Pui, D.; Kuehn, T. "Laboratory and On-Road Evaluations of Cabin Air Filters Using Number and Surface Area Concentration Monitors. "Environ. Sci. Technol., 42 (11), 4128 (2008)";

[11] Piera, E; et al. " $\mathrm{TiO}_{2}$ deactivation during gas-phase photocatalytic oxidation of ethanol. "Catal. Today, 76 (2-4), 259-270 (2002)";

[12] Technical Committee On Road Tunnels, "Pollution by nitrogen dioxide in road tunnels", reference 05.09.B, PIARC 2000;

[13] UNI 11247, "Determination of the degradation of nitrogen oxides in the air by inorganic photocatalytic materials: continuous flow test method", Milan, pp. 1-11 (2009);

[14] ISO 679, "Cement - Test methods - Determination of strength"( 2009);

[15] De Marco T. et Al. "Use of Photocatalytic Products for Sustainable Construction Development. SCMT3 Third International Conference on Sustainable Materials and Technologies. August 18 - 21, 2013, Kyoto, Japan;

[16] Fava G., et Al..” Photocatalytic Action of Water-Based $\mathrm{TiO}_{2}$ Paint Inside a Highway tunnel. European Symposium on Photocatalysis, September 2011 P. 5.8 Cite' Mondiale Bordeaux - France. 